\title{
Protein DBF4 homolog A
}

National Cancer Institute

\section{Source}

National Cancer Institute. Protein DBF4 homolog A. NCI Thesaurus. Code C28671.

Protein DBF4 homolog A (674 aa, $77 \mathrm{kDa}$ ) is encoded by the human DBF4 gene. This protein plays a role in DNA replication and cell proliferation and is required for the progression of S phase during mitosis. 